\title{
Modern data acquisition of the contaminated landscape cover
}

\author{
J. Hulka, I. Cespirova and Z. Prouza \\ SURO, National Radiation Protection Institute, Bartoskova 28, Praha 4, Czech Republic
}

\begin{abstract}
Aim of the work was analysis of the modern and rapid data acquisition methods for agricultural countermeasures, feedstuff restrictions and clean-up of large contaminated areas $\left(10^{4}-10^{5} \mathrm{~km}^{2}\right)$ after accident in a nuclear power reactor. Acquiring and generating agricultural reliable data especially based on satellite technology and analysis of landscape contamination (computer code vs. in situ measurements, airborne and/or terrestrial mapping of contamination) are discussed.
\end{abstract}

\section{INTRODUCTION}

The fallout from an accident in a nuclear power reactor or from nuclear weapons may contaminate a large area $\left(10^{4}-10^{5} \mathrm{~km}^{2}\right)$. To find out quickly the extent and magnitude of the dispersion of radioactive materials is a difficult task, although the modern computer codes for dispersion are more and more sophisticated. Timely countermeasures are important in an emergency for reducing exposure. Before these countermeasures can be carried out, the true extent of hazard should be known.

The agricultural countermeasures, foodstuff restrictions and clean-up of contaminated areas belong to major countermeasures in the late phase of a nuclear or radiological accident. If long-lived radionuclides have been dispersed in the environment, it is important to have duly knowledge of land cover contamination for well-timed planning of these measures.

Aim of the work was analysis of the modern and rapid data acquisition methods.

The research project includes:

- analysis of acquiring and generating agricultural reliable data,

- analysis of landscape contamination (computer codes, in situ airborne and/or terrestrial mapping of contamination),

- maps and databases of plant contamination for informed decision making.

\section{MATERIALS AND METHODS}

\subsection{Acquiring and generating agricultural reliable data}

To obtain reliable agricultural data (it means - on not only the types, but also the quality, quantity and location of the resources) is important information for the implementation of effective management decisions. There are several possibilities of data acquiring and generating e.g.:

- national databases and statistics - if exist (national, regional or district level); reliability and validity of these date are often questionable, however, therefore validation in case of emergency is necessary,

- aerial remote sensing technology,

- satellite technology.

Just satellite technology is now developing very fast and is important factor in the improvement of the present systems of acquiring and generating agricultural data in case of emergency. It provides imagery data at different spatial, spectral and temporal resolutions for agriculture and crop assessment, change detection, environmental analysis, landscape mapping, yield determination and soils analysis. Vegetation analysis (vegetation images) show crop growth, changes as the season progresses and 
abnormalities. The classifications (supervised or unsupervised) are needed, where the pixels of an image are sorted into classes and each class is given a unique attribute defined by the spectral "signatures". Using the distinct spectral signature of plants with low reflectance in the visible $(0.4-0.7 \mu \mathrm{m})$ and very high reflectance in the near infrared region $(0.7-1.2 \mu \mathrm{m})$ of the solar spectrum, the spectral contrast can be used for identifying the presence of green vegetation and evaluating some characteristics through various vegetation indices. Many satellites are prepared now to acquire such data [1]. ASTER, Modis (satellite Terra), and Quick bird were tested for use in accident. ASTER (Advanced Spaceborne Thermal Emission and Reflection Radiometer, high-resolution 15 to 90 square meters per pixel, images of the Earth in 14 different wavelengths of the electromagnetic spectrum, ranging from visible to thermal infrared light) seems to be appropriate at the moment. Scheduling and timing of image acquisition is very important and not easy task, however.

Once data has been collected and implemented into a mapping environment such as GIS, they are valuable, when used in conjunction with other data for management and control.

\subsection{The analysis of landscape contamination}

The first estimations of radiological impact during pre-release or release phase and information on landscape contamination are based on dispersion and deposition model. The main task of the codes is to predict projected release to the atmosphere (more or less conservatively expected) and to generate maps and tables with predicted contamination in the surrounding countryside under various circumstances. It allows early screening of possible strategies, to analyze feasibility and justification of measures identifying those, which may be effective in the short term and those which may be effective in the long term. The calculations performed by the computer codes with real meteorological data during vegetation period in the Czech republic showed ("este", HAVAR, RODOS are used in the Czech republic), that accident characterised by source term $10^{11}-10^{12} \mathrm{~Bq}$ can cause (under certain condition) very inhomogeneous contamination on territory of more $10^{4} \mathrm{~km}^{2}$, which exceeds levels for feedstuff and foodstuff regulation. Although the modern computer codes for dispersion are sophisticated, the true extent of hazard should be verified by real measurements in the landscape, before countermeasures would be carried out.

Several methods of acquiring data on contamination land cover are in using (terrestrial mapping by ground-based measurement of mobile groups), however airborne gamma spectrometry with highly sensitive radiation spectrometers mounted in aircraft to record radiation fields is excellent tool for finding out the extent and magnitude of the contamination in time. The combination of rapid measurement (short acquisition time $\sim 1 \mathrm{~s}$ ), high velocity, high fields of view etc. [2,3] results in area sampling rates $\left(10^{7}-10^{8} \mathrm{~m}^{2} \mathrm{~h}^{-1}\right)$. Beside this, the mass activity of plant (crops) could be estimate by means of airborne estimation of land cover contamination and crop yield obtained e.g. from satellite estimation. The effectiveness is many orders of magnitude higher than what can be achieved using conventional ground-based measurement methods (Czech ground-based mobile group supported by laboratory are able to analyse some 1000 samples per day).

In a case of large-scale nuclear power plant accident and presence of many radionuclides according accident scenarios, the analysis of the event is of crucial importance. Airborne gamma spectrometry NaI (Tl) or HpGe are prepared to estimate surface (land cover) contamination, however $\mathrm{NaI}(\mathrm{Tl})$ radiation spectrometer may become not able to differentiate individual radionuclides in case of complex spectra in the phase at least within 1-2 months after accident. Therefore sophisticated methods are necessary.

Airborne semiconductor gamma spectrometry is an excellent tool. If this system is not available, the rough estimate of surface deposition (and mass contamination of a crop) can be done by airborne doserate measurement by means of conversion coefficients (dose rate at height of flight /surface activity) and radionuclide vector (of crucial isotopes $\mathrm{I}, \mathrm{Te}, \mathrm{Cs}, \mathrm{Ru}$, etc.) estimated by laboratory or in situ measurements. 
Preliminary calculations of detection limits were done according to Currie method assuming a uniform source distribution on the surface, height of 100 meters, and 1 second integration time - that means very rapid measurement. The comparison [4] of semiconductor airborne gamma spectrometry (Huge efficiency 25\%), and bare airborne dose rate measurement (assuming $50 \mathrm{nGy} / \mathrm{h}$ as a signal) showed, that minimum identifiable activities (e.g. for $\mathrm{Cs}^{137}$ ) are in range

- $\left(20-30 \mathrm{kBq} / \mathrm{m}^{2}\right)$ while using airborne semiconductor spectrometry,

- $\left(300-500 \mathrm{kBq} / \mathrm{m}^{2}\right)$ while using bare airborne dose rate measurement.

Minimum identifiable activities for airborne scintillation spectrometry $\left(\mathrm{NaI}(\mathrm{Tl}) 4 \times 4 \mathrm{dm}^{3}\right)$ are in range $\left(2-6 \mathrm{kBq} / \mathrm{m}^{2}\right)$, however not applicable in case of complex spectra.

Considering mentioned minimum identifiable surface activities for very rapid measurement (short acquisition time $\sim 1 \mathrm{~s}$, corresponding area sampling rates $10-10^{2} \mathrm{~km}^{2} \mathrm{~h}^{-1}$ ) and considering typical crop yields in range $0.5-5 \mathrm{~kg} / \mathrm{m}^{2}$, minimum identifiable mass activities of plant (crops) are estimated within the range of tens $\mathrm{kBq} / \mathrm{kg}$ while using airborne semiconductor spectrometry and within the range of hundreds $\mathrm{kBq} / \mathrm{kg}$ while using airborne dose rate measurement. This is the starting point for scheduling of airborne monitoring and screening strategy, the system could classify territory $10^{4} \mathrm{~km}^{2}$ during the week.

\section{CONCLUSION}

In case of large-scale nuclear power plant accident a complex contamination of land cover by many radionuclides have to be expected. Aim of research is developing aids for management decision. The system based on modern combination of satellite acquiring of agricultural data and airborne radiometric measurements are an excellent choice. The system can yield data and maps in time. This information can help the farmers and agricultural managers to make informed decisions about the most feasible solution. In addition to highlighting problematic areas, images will also help monitor the effectiveness of any remediation which may be implemented.

\section{Acknowledgments}

The authors are grateful to Dr P. Doubrava for valuable discussions and help in satellite science. This research has been supported by the grant of the SONS 1/2008.

\section{References}

[1] P. Doubrava, Ověření metod dálkového prủzkumu Země v oblasti krizových situací, Report GEOAIR, Praha 2007.

[2] D.C.W. Sanderson., Demonstration of the European capability for airborne gamma spectrometry. Results from the ECCOMAGS exercise, Radiation Protection Dosimetry (2004), Vol. 109, $119-125$.

[3] H. Toivonen, Airborne gamma spectrometry - towards integration of European operational capability. Radiation Protection Dosimetry 2004; Vol. 109(1-2):137-40.

[4] J. Hủlka and I. Češpírová, Metody hodnocení kontaminovaného území po radiaění havárii význam struktury a funkce krajinného krytu, Report SURO (in Czech), Prague 2008. 
